\title{
Polar cap patches observed during the magnetic storm of November 2003: observations and modeling
}

\author{
C. E. Valladares ${ }^{1}$, T. Pedersen ${ }^{2}$, and R. Sheehan ${ }^{1}$ \\ ${ }^{1}$ Institute for Scientific Research, Boston College, Chestnut Hill, Massachusetts, USA \\ ${ }^{2}$ Space Vehicle Directorate, Air Force Research Laboratory, Kirtland Air Force Base, New Mexico, USA \\ Correspondence to: C. E. Valladares (cesar.valladares@bc.edu)
}

Received: 13 March 2015 - Revised: 29 July 2015 - Accepted: 13 August 2015 - Published: 14 September 2015

\begin{abstract}
We present multi-instrumented measurements and multi-technique analysis of polar cap patches observed early during the recovery phase of the major magnetic storm of 20 November 2003 to investigate the origin of the polar cap patches. During this event, the Qaanaaq imager observed elongated polar cap patches, some of which containing variable brightness; the Qaanaaq digisonde detected abrupt $N_{m} F_{2}$ fluctuations; the Sondrestrom incoherent scatter radar (ISR) measured patches placed close to but poleward of the auroral oval-polar cap boundary; and the DMSPF13 satellite intersected topside density enhancements, corroborating the presence of the patches seen by the imager, the digisonde, and the Sondrestrom ISR. A 2-D cross-correlation analysis was applied to series of two consecutive red-line images, indicating that the magnitude and direction of the patch velocities were in good agreement with the SuperDARN convection patterns. We applied a back-tracing analysis to the patch locations and found that most of the patches seen between 20:41 and 21:29 UT were likely transiting the throat region near 19:41 UT. Inspection of the SuperDARN velocities at this time indicates spatial and temporal collocation of a gap region between patches and large $\left(1.7 \mathrm{~km} \mathrm{~s}^{-1}\right)$ lineof-sight velocities. The variable airglow brightness of the patches observed between 20:33 and 20:43 UT was investigated using the numerical Global Theoretical Ionospheric Model (GTIM) driven by the SuperDARN convection patterns and a variable upward/downward neutral wind. Our numerical results indicate that variations in the airglow intensity up to $265 \mathrm{R}$ can be produced by a constant $70 \mathrm{~m} \mathrm{~s}^{-1}$ downward vertical wind.
\end{abstract}

Keywords. Ionosphere (instruments and techniques)

\section{Introduction}

Early measurements of polar cap densities conducted at Thule, Greenland ( $86^{\circ}$ mlat), indicated the presence of large regions containing enhanced ionization, named polar cap patches, occurring preferentially during magnetically disturbed periods ( $B_{z}$ south conditions) (Buchau et al., 1983). During the last 30 years, measurements of polar cap patches have provided information on their typical horizontal dimensions (between 100 and $1000 \mathrm{~km}$ ) (Weber et al., 1984), their prevailing motion (antisunward), and their variety of shapes with a preference for cigar-shaped forms containing a major axis aligned in the dawn-dusk direction. During the 1980s, it was found that the density within the patches reached $10^{6} \mathrm{el} \mathrm{cm}^{-3}$ at $250 \mathrm{~km}$ altitude, while outside the ionization dropped below $10^{5} \mathrm{el} \mathrm{cm}^{-3}$ at $400 \mathrm{~km}$ altitude. Month-long experiments indicated that the hourly pattern of patch occurrence coincided with the universal time that the dayside auroral oval moves further down to lower geographic latitudes. This indicated that the solar-produced sub-auroral ionosphere was the source region of the patches (Buchau et al., 1985). Measurements at Chatanika and Sondrestrom conducted by Foster and Doupnik (1984) and Kelly and Vickrey (1984) confirmed that sub-auroral densities intrude through the dayside throat region, forming a continuous and long tongue of ionization (TOI). However, the patchy nature of the density enhancements implied the presence of a formation mechanism able to fragment the TOI.

The first formulation of a patch-formation mechanism consisted of sudden reversals of the $B_{y}$ and/or $B_{z}$ interplanetary magnetic field (IMF) components (Tsunoda, 1988). Shortly afterwards, numerical simulations confirmed that varying the convection pattern due to the migration of the 
reconnection point and a consequent redirection of the tension force (Sojka et al., 1993) or a resizing of the polar cap (Anderson et al., 1988), as commonly occurs when $B_{z}$ switches sign, could result in a fragmented TOI resembling the observed polar cap patches. However, the observational fact that patches commonly occur in a succession of several polar cap patches separated by time intervals as short as $10 \mathrm{~min}$ raised some doubts about the efficiency of these mechanisms. More comprehensive measurements were conducted in the 1990s combining instruments placed at the center of the polar cap and observatories located at the boundary of the auroral oval and polar cap, such as the Sondrestrom and EISCAT incoherent radars. These investigations demonstrated that large plasma jets are effective in creating a region of depleted densities across the TOI by enhancing the $\mathrm{O}^{+}$recombination coefficient and transporting less dense plasma from later local times (Rodger et al., 1994; Valladares et al., 1994, 1996). Observations gathered mainly from EISCAT, but also from the EISCAT Svalbard radar (ESR), have confirmed the important role of transient magnetic reconnection in bringing plasma into the polar cap and creating patches (Lockwood and Carlson, 1992; Carlson et al., 2002, 2004, 2006). Lorentzen et al. (2010) found that for each poleward-moving auroral form (PMAF) there existed enhanced ionization moving into the polar cap, giving more credence to the transient reconnection. In addition, Carlson et al. (2007) stressed the role of shear-driven instabilities in first rapidly structuring the plasma, after which gradient drift instabilities develop based on these large-scale seeds. More recently, Carlson (2012) pointed out the role of velocity shears to more efficiently separate the continuous dayside plasma in regions of low and high density and simultaneously seed other plasma-structuring processes. Oksavik et al. (2010) tracked the motion of polar cap patches from the dayside Svalbard sector to the nightside Alaska sector to find a continuous growth of the irregularities across the polar cap. MacDougall and Jayachandran (2007) used $f_{0} F_{2}$ values from several stations located in the Canadian Arctic to propose a mechanism for patch generation in which density enhancements were produced by low-energy electron precipitation as the plasma returns from midnight around the dawn convection cell. Cusp/cleft particle precipitation can also form polar cap patches (Walker et al., 1999). In other situations when the IMF is directed northward, cusp precipitation is able to form a patch in a stirred lobe cell (Oksavik et al., 2006). Moen et al. (2006) used radar and all-sky observations to find that downward Birkeland current sheets are able to segment the TOI, creating a sequence of patches at latitudes equatorward of the cusp/cleft region. Bust and Crowley (2007) used a trajectory analysis method and an assimilation scheme to conclude that a sequence of patches observed at Svalbard on 12 December 2001 had been transported toward noon from the morning and afternoon sectors, and sometimes the patch densities originated at $62^{\circ}$ geographic latitude. Bust and Crowley (2007) also indicated the need to use first-principle numerical models to associate ionospheric measurements conducted at separate locations to investigate the patch origin, and to forecast the decay of the large-scale enhanced densities. These new investigations emphasize a new trend in polar cap patch research that tries to attain polar-cap-wide coverage and to complement experimental measurements with numerical assimilations. During magnetically active days, large-scale gravity waves, generated in the auroral zone, propagate equatorward (Hocke and Schlegel, 1996) or circulate across the polar cap (Johnson et al., 1995). However, the interaction between gravity waves and polar cap patches has not been reported before.

This paper presents observations of polar cap patches conducted at Qaanaaq and Sondrestrom as well as ancillary data collected by the SuperDARN radars and DMSP satellites during the recovery phase of the major magnetic storm of 20 November 2003. We present observations of $630.0 \mathrm{~nm}$ airglow, digisonde bottomside densities, and UHF scintillations conducted near the center of the polar cap at Qaanaaq, Greenland, in which series of polar cap patches were detected moving with the global convection (Sect. 3). The goals of this paper are to document the morphology and dynamics of polar cap patches during extremely disturbed conditions, to describe brightness changes of patch airglow, and to postulate that plasma dynamics near noon were responsible for the patch fragmentation on 20 November 2003. This paper also introduces a method of determining the patch velocity using a 2-D cross-correlation analysis of two adjacent $630.0 \mathrm{~nm}$ images (Sect. 4), a back-tracing trajectory analysis (Sect. 5), and forward-in-time modeling of the patch densities and $630.0 \mathrm{~nm}$ airglow intensities (Sect. 6).

\section{The super-storm of 20 November 2003}

The largest geomagnetic storm of solar cycle 23 occurred on 20 November 2003, caused by a fast and wide coronal mass ejection (Gopalswamy et al., 2005). The storm started at 07:28 UT with the arrival of the shock and reached a minimum SYM-H index (equivalent to $1 \mathrm{~min}$ Dst) of about $-490 \mathrm{nT}$ at 18:18 UT (Basu et al., 2007) (see Fig. 1 of Gopalswamy et al., 2005, for a display of Dst index and the solar wind parameters). During the main phase of the storm, the IMF $B_{z}$ reached $-52 \mathrm{nT}$ at 15:15 UT. During our observations the IMF $B_{z}$ was nearly constant and about $-20 \mathrm{nT}$ (20:00-22:00 UT). The IMF $B_{y}$ was negative and about $-20 \mathrm{nT}$ after 19:30 UT. During major magnetic storms, the interaction between the solar wind and the magnetosphere causes a change in the region 1 and 2 currents. Under these conditions, the shielding characteristics are varied, allowing an instantaneous penetration of an electric field from high latitude to the middle and low latitudes. Several authors have described the characteristics of the ionosphere and atmosphere that prevailed during the main and recovery phases of the 20 November 2003 geomagnetic storm (Foster et al., 

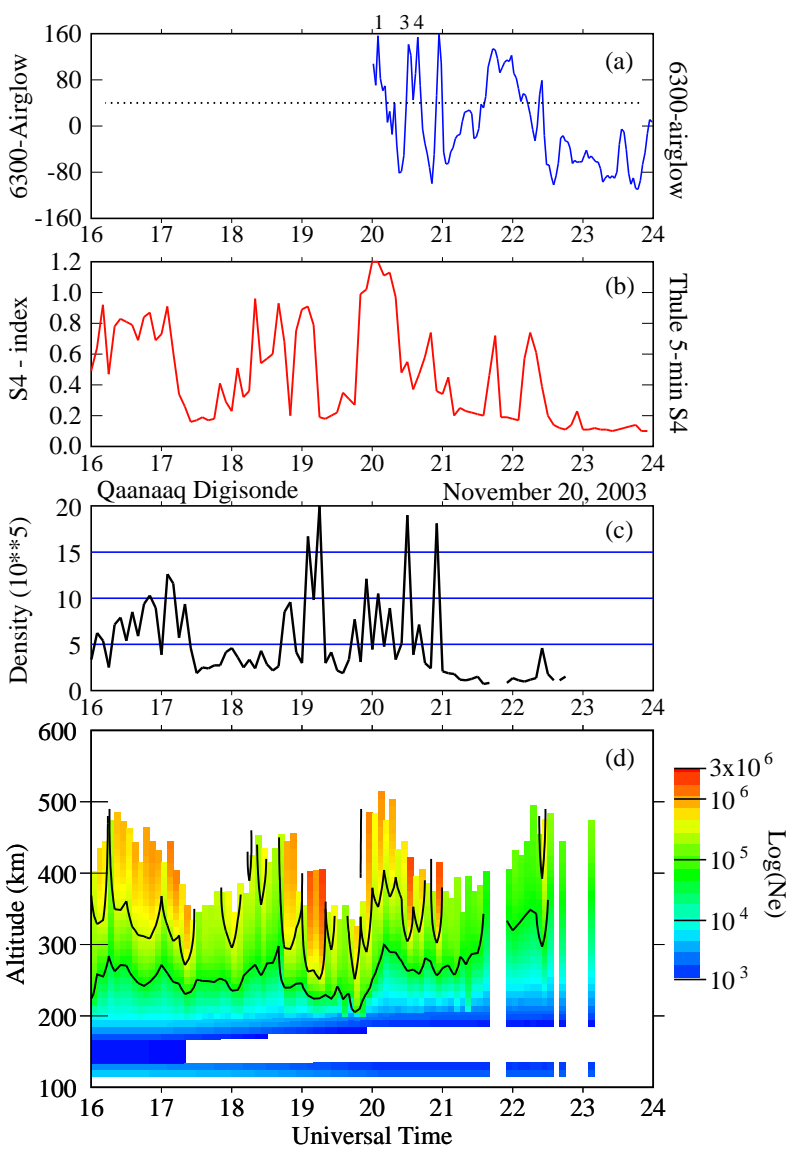

Figure 1. (a)Relative values of $630 \mathrm{~nm}$ airglow emissions, (b) UHF S4 scintillation index, (c) peak density measured by the digisonde, (d) and color-coded bottomside density profiles. Numbers above panel (a) refer to the time when the airglow associated with patches 1,3 , and 4 passed overhead the Qaanaaq station.

2005; Meier et al., 2005; Crowley et al., 2006; Basu et al., 2007). Foster et al. (2005) presented global displays of the ionospheric total electron content (TEC) to demonstrate that the dayside source of the TOI is the plume of storm enhanced densities (SEDs) that is transported from lower latitudes in the post-noon sector by the sub-auroral electric field. During the major geomagnetic storm of 20 November 2003 a pronounced SED entered the polar cap in the America sector near 18:00 UT, as observed by Foster et al. (2005). They presented 2-D maps of equivalent vertical TEC from a network of GPS receivers to demonstrate that SEDs in fact penetrate the polar caps, forming a TOI containing plasma densities with $h_{m} F_{2}$ and $N_{m} F_{2}$ values typical of the midlatitude ionosphere. They indicated that the SED density was transported from low latitudes by the sub-auroral disturbance electric field acting in the post-noon sector. This paper suggests that the continuous sub-auroral TOI presented by Foster et al. (2005) breaks off into polar cap patches when it enters or is about to enter into the polar cap. We use drifts measured by the SuperDARN radars and time-reversed trajectory trac- ing of the patches observed at Qaanaaq to imply that the TOI fragmentation (i.e., patch formation) occurs in the noon sector.

\section{Observations of the polar cap on 20 November 2003}

Optical, radar, and scintillation observations were carried out in the central polar cap at Qaanaaq, Greenland $\left(77.47^{\circ} \mathrm{N}\right.$ $69.27^{\circ} \mathrm{W} ; \sim 86^{\circ}$ mlat (magnetic latitude); 03:10 UT midnight magnetic local time) using a high-sensitivity all-sky imager, a digisonde, and a system of UHF scintillation receivers, respectively. The imager consists of an all-sky lens telecentrically coupled to a 4 in. $(100 \mathrm{~mm})$ filter wheel containing narrow-band $(\sim 2 \mathrm{~nm})$ filters. In the mode used, light passing through the filters was re-imaged onto a thermoelectrically cooled bare-CCD detector operated at $-40^{\circ} \mathrm{C}$. Data were corrected for instrument vignetting and Van Rhijn brightening and converted to units of rayleighs based on a laboratory calibration of the instrument against a calibration source traceable to the National Institute of Standards and Technology. The Sondrestrom incoherent scatter radar (ISR) $\left(67.0^{\circ} \mathrm{N}, 50.9^{\circ} \mathrm{W} ; 75^{\circ}\right.$ mlat; 01:57 UT midnight magnetic local time) observed the electron densities and ion drift velocities. The Northern Hemisphere SuperDARN radars provided plasma drifts and high-latitude convection patterns. The DMSP satellite measured the characteristics of the electron and ion particle populations and the direction of the cross-track drift velocities to help identify the boundaries of the polar cap.

\subsection{Qaanaaq observations}

Figure 1 shows the value of $630.0 \mathrm{~nm}$ airglow emissions, the S4 scintillation index, the peak density of the F region, and density profiles of the F-region bottomside. The last two observables were measured by the Qaanaaq digisonde operating in a 5 min cadence time. The bottom panel also displays two iso-density contour traces corresponding to $10^{5}$ and $10^{6} \mathrm{~cm}^{-3}$. A prominent feature in this plot is the rapid variability in $h_{m} F_{2}$ and $N_{m} F_{2}$. Between 20:00 and 21:00 UT the F-region peak varied from 500 to $400 \mathrm{~km}$ altitude and a series of density enhancements was detected as the digisonde peak density varied between $2 \times 10^{5}$ and $2 \times 10^{6} \mathrm{~cm}^{-3}$. After 21:00 UT, and during the recovery phase of the storm, the number density continues to display rapid altitude variations. Several authors (e.g., Weber et al., 1984; Crowley, 1996) have defined polar cap patches to be 2-10 times larger than the background density in the polar ionosphere. Here, we classify a polar cap patch when the density enhances by a factor of at least 2; simultaneously, the imager detects discrete regions of airglow $40 \mathrm{R}$ above the average and the scintillation index increases above the noise level. However, we indicate that some patches may have a low level of scintillations due to a low density or small density gradient. 
On 20 November the Qaanaaq imager started operations shortly after 20:00 UT. Figure 1a displays relative values of $630.0 \mathrm{~nm}$ intensities that were calculated by averaging four pixels taken directly overhead the station. The calibrated values of the airglow emissions have the average intensity of each image subtracted, a value equal to $1200 \mathrm{R}$. The dotted line placed at $40 \mathrm{R}$ indicates our designated threshold values for possible patch detections. Values above this line are defined as enhanced airglow levels that could be produced by patches transiting across the imager field of view. Two large positive excursions observed between 20:15 and 21:00 UT correlate well with increases in the number density (Fig. 1c). S4 scintillation indices above 0.6 are observed 5-10 min prior to the density enhancements due to the spatial separation between the scintillations pierce point and the overhead direction. A third airglow increase is seen between 21:40 and 22:10; this is flanked by increases in the S4 index. No density measurements were conducted at this time as a short period of absorption from the D layer inhibited the F-region echoes between 21:40 and 21:55 UT. Panel b shows 5 min averaged scintillation measurements obtained at Qaanaaq by the use of $250 \mathrm{MHz}$ transmissions from quasi-stationary beacon satellites (Basu et al., 1998). After 20:00 UT, the $350 \mathrm{~km}$ altitude sub-ionospheric intersection of the scintillation link was located at $77.6^{\circ} \mathrm{N}, 77^{\circ} \mathrm{W}$ and $\sim 200 \mathrm{~km}$ west of the Qaanaaq site (indicated by a white dot and the letters Sc in Fig. 2). Panels $1 \mathrm{c}$ and d show the peak density and bottomside density profiles measured by the digisonde at Qaanaaq.

\subsection{Qaanaaq images}

Figure 2 shows a selected $630.0 \mathrm{~nm}$ image obtained early during the observations of 20 November 2003. Date and time information is printed on the top left side of the image. The two black lines intersecting at $90^{\circ}$ in the center of the image indicate the direction of geographic north and east. Two white dots are used to indicate the center of the image field of view (Q) and the sub-ionospheric intersection of the scintillation measurements $(\mathrm{Sc})$. At the beginning of the observations (20:00 UT), the sunward direction is toward geographic west and the dawn-dusk meridian almost aligned to the northsouth axis. A small number of clouds and some haze were present during the early period of the observations. However, after 20:20 UT, the sky was devoid of tropospheric interferences. Weber et al. (1984), Fukui et al. (1994), and Valladares et al. (1998) indicated that, near the center of the polar cap, the patches are preferentially elongated and quite often adopt a cigar-shaped form with the major axis closely aligned in the dawn-dusk direction. This type of patch configuration is seen in the image of 20:21 UT (Fig. 2), where a long and elongated patch, closely aligned to the magnetic north-south direction, is observed extending across the imager field of view. Two other smaller airglow enhancements are detected on the western half of the image.

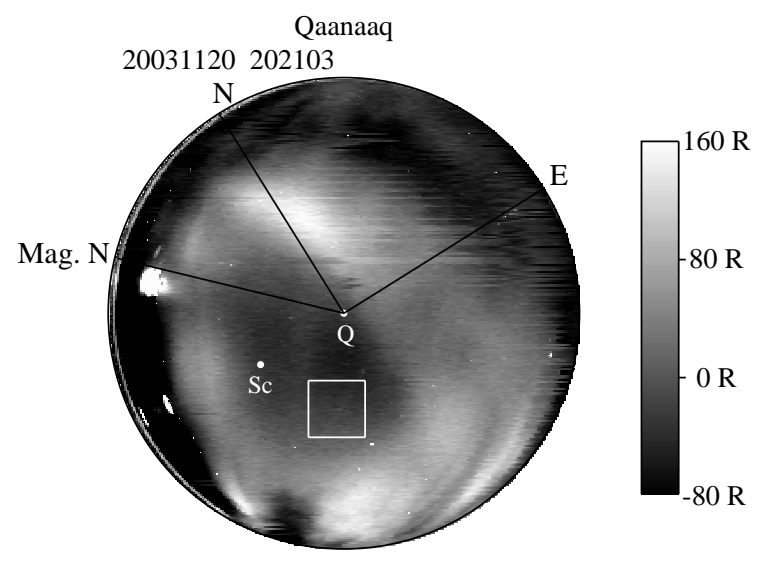

Figure 2. $630.0 \mathrm{~nm}$ airglow image from Qaanaaq, Greenland, observed at 20:21 UT on 20 November 2003. The white dots correspond to the zenith direction $(\mathrm{Q})$ and the sub-ionospheric intersection point of the scintillation system $(\mathrm{Sc})$. The white square displayed in the lower part of the image indicates the extension of a $32 \times 32$ pixel array used in the correlation analysis.

Each of the $630.0 \mathrm{~nm}$ images of Fig. 3 was processed by removing the average value of all pixels within the imager field of view and normalizing the intensity with respect to the image standard deviation $(\sigma)$. To avoid systematic effects a constant $\sigma$ value equal to $80 \mathrm{R}$ was employed to normalize the images presented in Figs. 3 and 4. Three contour levels serve to indicate the locations where airglow intensities reach the relative levels of $50 \mathrm{R}$ (blue), $80 \mathrm{R}$ (green), and $110 \mathrm{R}$ (blue) values. Note also that the contour levels have been restricted to elevations larger than $20^{\circ}$. The image sequence of Fig. 3 shows several polar cap patches with atypical morphological characteristics. It displays the "appearance" of new patches, and sudden changes of the patch brightness that have never been reported before. The first image of the sequence (20:23:03 UT) trails the image of Fig. 2 by 2 min. This image shows that the north-south-elongated patch (labeled 1) has drifted eastward and is now located $\sim 200 \mathrm{~km}$ east of zenith. Two additional patches are also present in this image: (1) a small patch (labeled 2) placed at the northern side adjacent to patch 1 and (2) a bright east-west segment (labeled 3) located near the southern edge of patch 1 . The subsequent three images (20:25-20:29 UT) show patch 1 moving antisunward (eastward), and its apparent width, in the imager frame of reference, diminishing as it moves toward lower-elevation viewing angles that have coarser spatial resolution. Images recorded between 20:23 and 20:47 UT display the growth, brightening, and exit of patch 2 as it transits across the imager field of view. As time progresses, patch 2 is seen to extend further south and occupy a much larger area (20:35 UT), then move continuously toward the east and reach the eastern edge of the imager (20:47 UT). It is important to note, as demonstrated below, that the SuperDARN convection velocity was directed antisunward (eastward) during this time. 

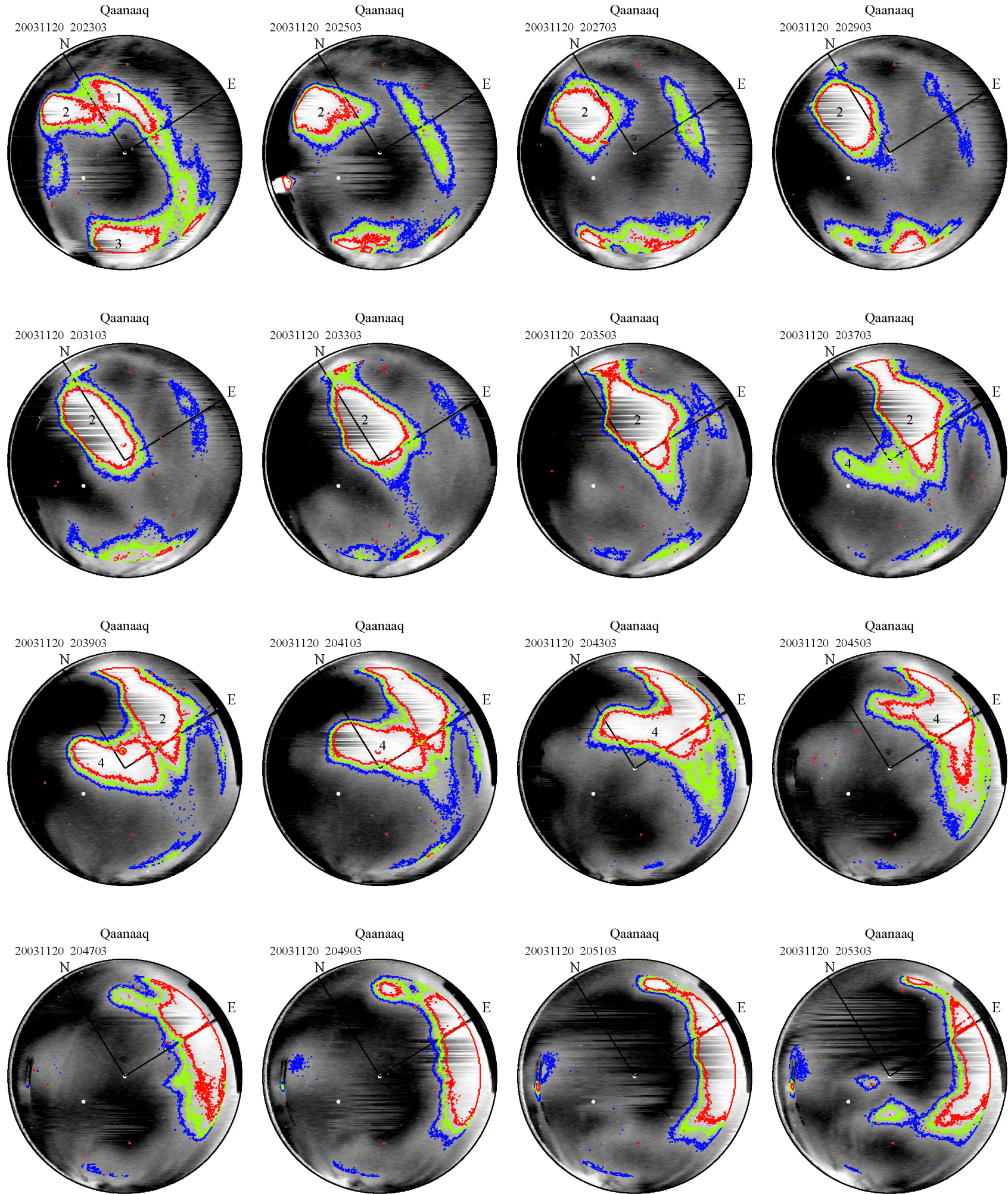

Figure 3. Sequence of images gathered at Qaanaaq, Greenland, between 20:23 and 20:53 UT during the recovery phase of the magnetic storm of 20 November 2003. 
Nevertheless, patch 2 "growth" was in the southward direction. The images of 20:37:03 and 20:39:03 UT show the appearance and brightening of a "new" patch (labeled 4) that intensifies near the western side of the patch that developed minutes before. Two additional observations support our hypothesis that the $630.0 \mathrm{~nm}$ emissions detected overhead the station at 20:37 UT correspond in fact to a polar cap patch: (1) before the appearance of patch 4 , very faint emissions were observed close to where the patch develops (see image for 20:35 UT), and (2) the peak density in Fig. 1c and d increases above $10^{6} \mathrm{~cm}^{-3}$. In addition, the contour level of $10^{5} \mathrm{~cm}^{-3}$ of Fig. 1d indicates that at 20:35 UT, the overhead F-region bottomside was at $240 \mathrm{~km}$ altitude, lower than the altitude $(280 \mathrm{~km})$ observed 20 min earlier.

\subsection{Sondrestrom densities}

On 20 November 2003 the Sondrestrom radar conducted a series of composite scans along two parallel planes. During composite scans both the azimuth (AZ) and elevation (EL) angles are varied accordingly to keep the lines of constant height parallel to a plane that embeds the vertical direction and the declination of the magnetic field above the radar site $\left(-27^{\circ}\right.$ from geographic north). Figure 4 presents the electron number density and the line-of-sight (LOS) velocities collected during two consecutive scans corresponding to the periods of 20:01:56-20:05:04 and 20:08:57-20:12:05 UT. In this figure the density contours have been projected to a plane in which the vertical axis is the true height and the horizontal line is the north-south distance along the geographic meridian. The initial values of the density contours were set to $10^{5} \mathrm{~cm}^{-3}$ and the spacing between both contour levels was also made equal to $10^{5} \mathrm{~cm}^{-3}$. Note that the top panel of Fig. 4 corresponds to the western scan and the bottom panel shows measurements conducted during the eastern scan. Due to the nature of the composite scans, the spatial (latitudinal) and height variability of the density are intermixed. However, the main features of the polar cap patches can be recovered based on the main property of the patches extending for hundreds of kilometers. The western scan shows a patch with a peak number density almost equal to $10^{6} \mathrm{~cm}^{-3}$ at $450 \mathrm{~km}$ altitude. This patch is placed between 0 and $400 \mathrm{~km}$ to the north and extends up to $850 \mathrm{~km}$ altitude. The eastern scan, conducted 7 min later, displays two density enhancements. The patch closer to the radar site has a peak value near $7 \times 10^{5} \mathrm{~cm}^{-3}$ at $500 \mathrm{~km}$ altitude and resides $\sim 300 \mathrm{~km}$ north of the radar site. The second patch is seen in the northern part of the eastern scan containing densities near $10^{6} \mathrm{~cm}^{-3}$ at $700 \mathrm{~km}$ north of the Sondrestrom site extending further north toward the direction of Qaanaaq. Figure 4 also shows the LOS velocities using blue (toward the radar) and red (away) arrows of different lengths according to the magnitude of the plasma velocity. The fact that the velocities are all blue (toward the radar) in the west scan and all red (away from it) in the east scan indicates that the plasma velocity was mainly directed
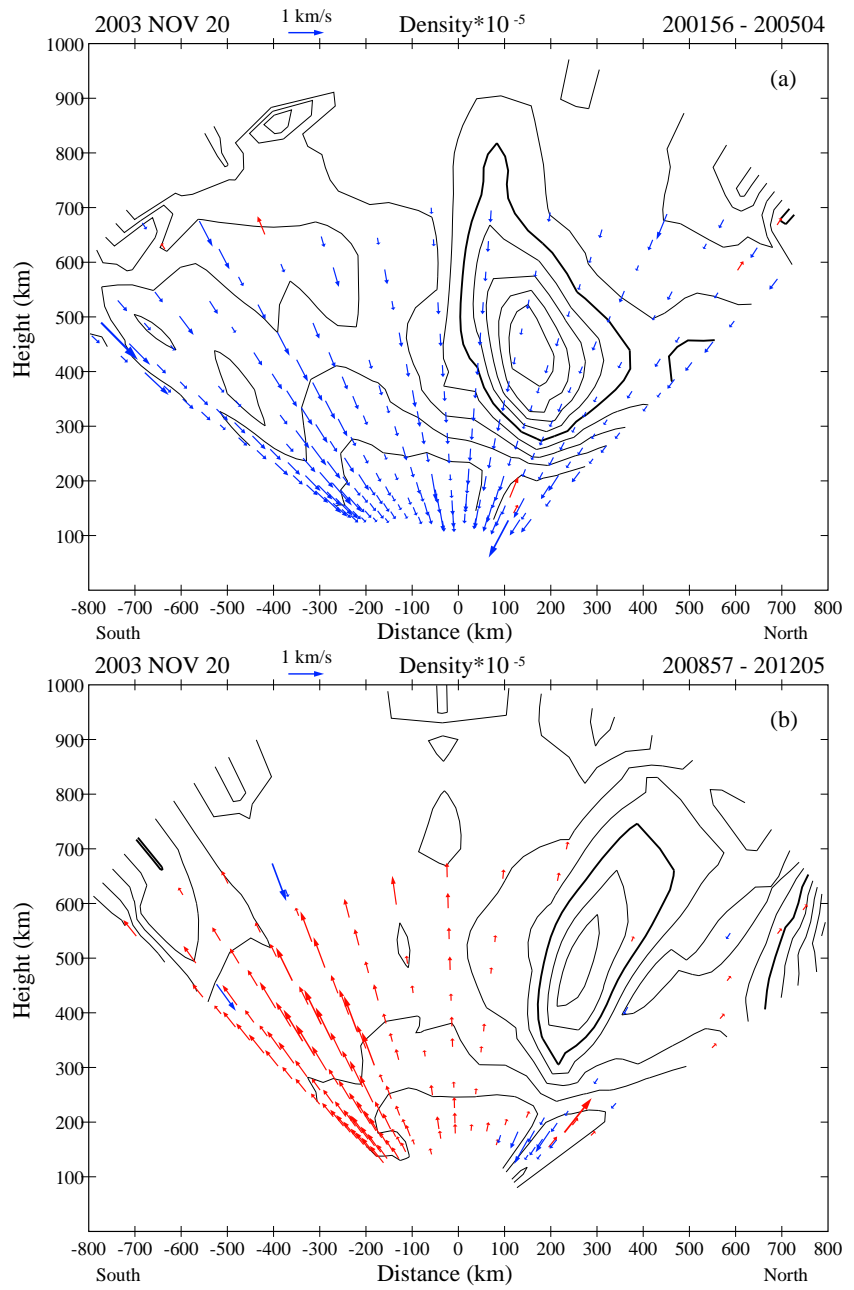

Figure 4. Number density and line-of-sight velocities measured by the Sondrestrom ISR on 20 November 2003, and during the time interval between 20:01:56 and 20:05:04 (west scan, top panel) and 20:08:57 and 20:12:05 UT (east scan, bottom panel). Negative (toward radar) velocities are indicated in blue, and positive (away from radar) velocities are displayed in red. Density contour lines are used to indicate levels spaced by $10^{5} \mathrm{~cm}^{-3}$. The thick contour line represents a density value equal to $5 \times 10^{5} \mathrm{~cm}^{-3}$. The radar antenna conducted composite scans in which azimuth and elevation were varied to keep the scan plane almost parallel to the magnetic meridian.

toward magnetic east and closely parallel to the boundary of the auroral oval and the polar cap. This interpretation is based on the nature of the composite scans in which the radar antenna is directed toward the west on the western scan and points toward the east on the eastern scan.

Figure 5 shows again some of the density contours presented in Fig. 4, but here the contour lines have been projected to a ground plane. The contours corresponding to $5 \times 10^{5}$ and $10^{6} \mathrm{~cm}^{-3}$ indicate that the radar bisected the patch, measuring the cross section of a long and east-westelongated patch. This figure also shows the ground projec- 

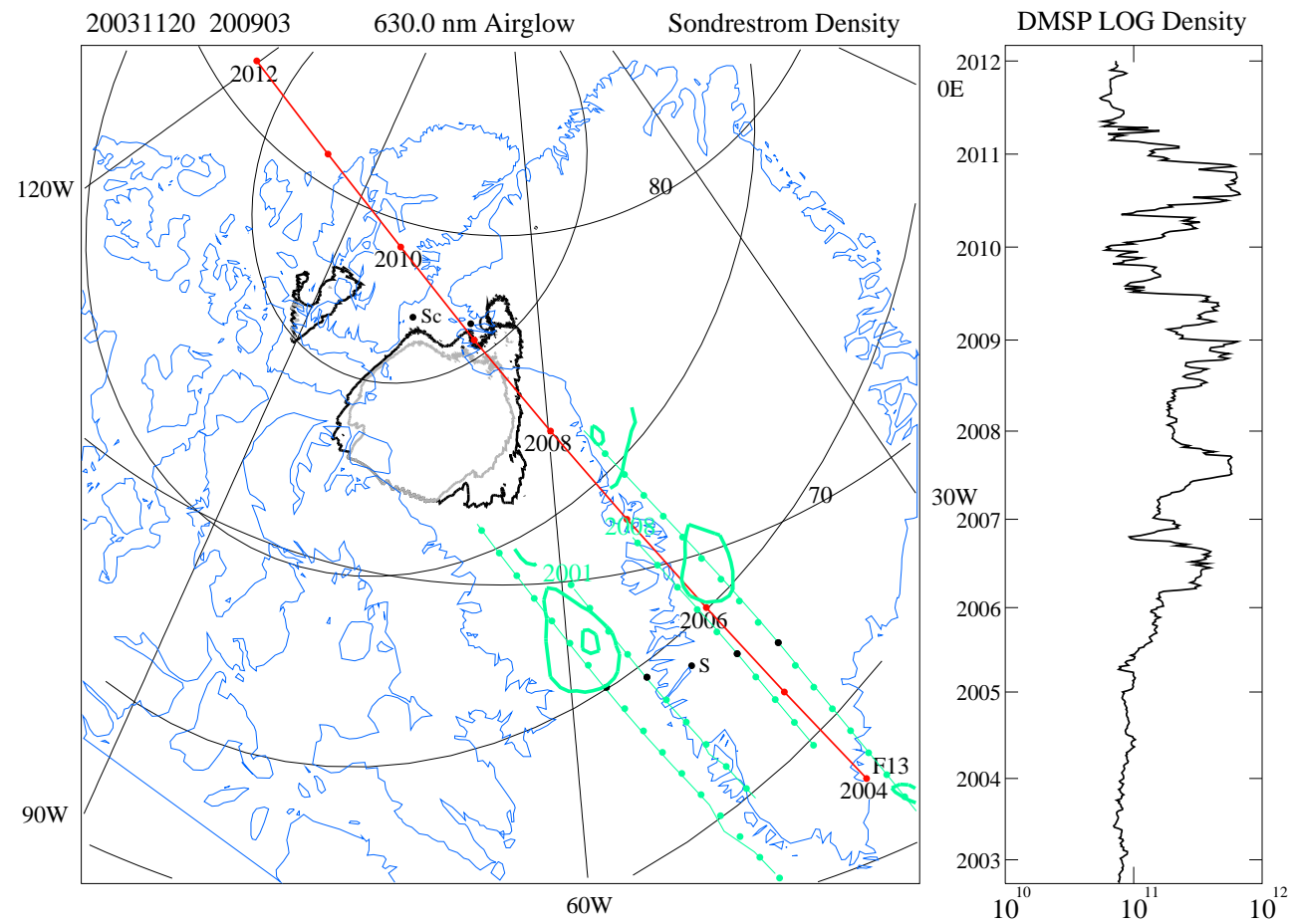

Figure 5. 630.0 nm airglow emissions (black and gray contours) from Qaanaaq, Greenland, observed at 20:09 UT on 20 November 2003 projected to $250 \mathrm{~km}$ altitude. The trajectory of the DMSP-F13 pass is plotted in red. The red dots indicate the minute at which the satellite passed near Qaanaaq. The density measure by F13 is shown in the right panel. Densities measured by the Sondrestrom radar during two consecutive composite scans are indicated in green.

tion (green line with dots) of the 300 and $500 \mathrm{~km}$ constant altitude for both scans. Figure 5 also includes the $630.0 \mathrm{~nm}$ emissions measured by the Qaanaaq imager, and the DMSPF13 satellite trajectory (red line) mapped along the B lines from $850 \mathrm{~km}$ altitude to the $\mathrm{F}$ region and then projected to the ground plane. The right panel shows in situ densities measured by the DMSP satellite and plotted according to the satellite trajectory as the satellite moved along in the geographic plot. Four density enhancements are displayed in the right panel clearly corresponding to the ISR density and airglow enhancements that were observed at Sondrestrom and Qaanaaq, respectively. Notice that the DMSP intersected the Sondrestrom east scan at 20:06 UT and later the Qaanaaq imager at 20:08 UT. It is evident that the first patch detected by DMSP-F13 at 20:06:10 UT corresponds to the density enhancement observed $350 \mathrm{~km}$ north and during the radar scan of 20:08:57 UT. The DMSP density enhancement at 20:07:20 UT is probably related to the density enhancement seen $700 \mathrm{~km}$ north of the radar site. The long density enhancement of 20:08:30 UT is associated with the airglow enhancement seen by the imager. A fourth patch detected by the DMSP satellite was almost outside and northward of the field of view of the Qaanaaq imager.

\subsection{DMSP measurements}

Figure 6 shows several parameters measured during the dusk-dawn DMSP-F13 pass, whose trajectory is displayed in Fig. 5. The top panel shows the four density enhancements that were mentioned above and were measured in the dusk side of the polar cap. A fifth density enhancement is seen in the dawn side of the polar cap at 20:12:10 UT, presenting a factor of 2 enhancement ratio. The dusk poleward boundary of the auroral precipitation is seen near $71^{\circ}$ mlat at 20:05 UT, marking the boundary of the auroral oval and the polar cap regions. Figure 5 suggests that this boundary (see DMSP trajectory at 20:05 UT) is placed about $200 \mathrm{~km}$ south of the Sondrestrom radar site and clearly equatorward of the density enhancements detected by the ISR. The DMSP drift velocities reverse from a sunward to an antisunward direction in a region equatorward of the particle boundary and are clearly antisunward within the polar cap. The DMSP particle data provide conclusive evidence that the density and airglow enhancements that were observed at Qaanaaq and Sondrestrom were well within the polar cap.

\section{Patch drift velocities}

We have calculated the drift velocity of the polar cap patches by using an algorithm that employs a 2-D cross-correlation 


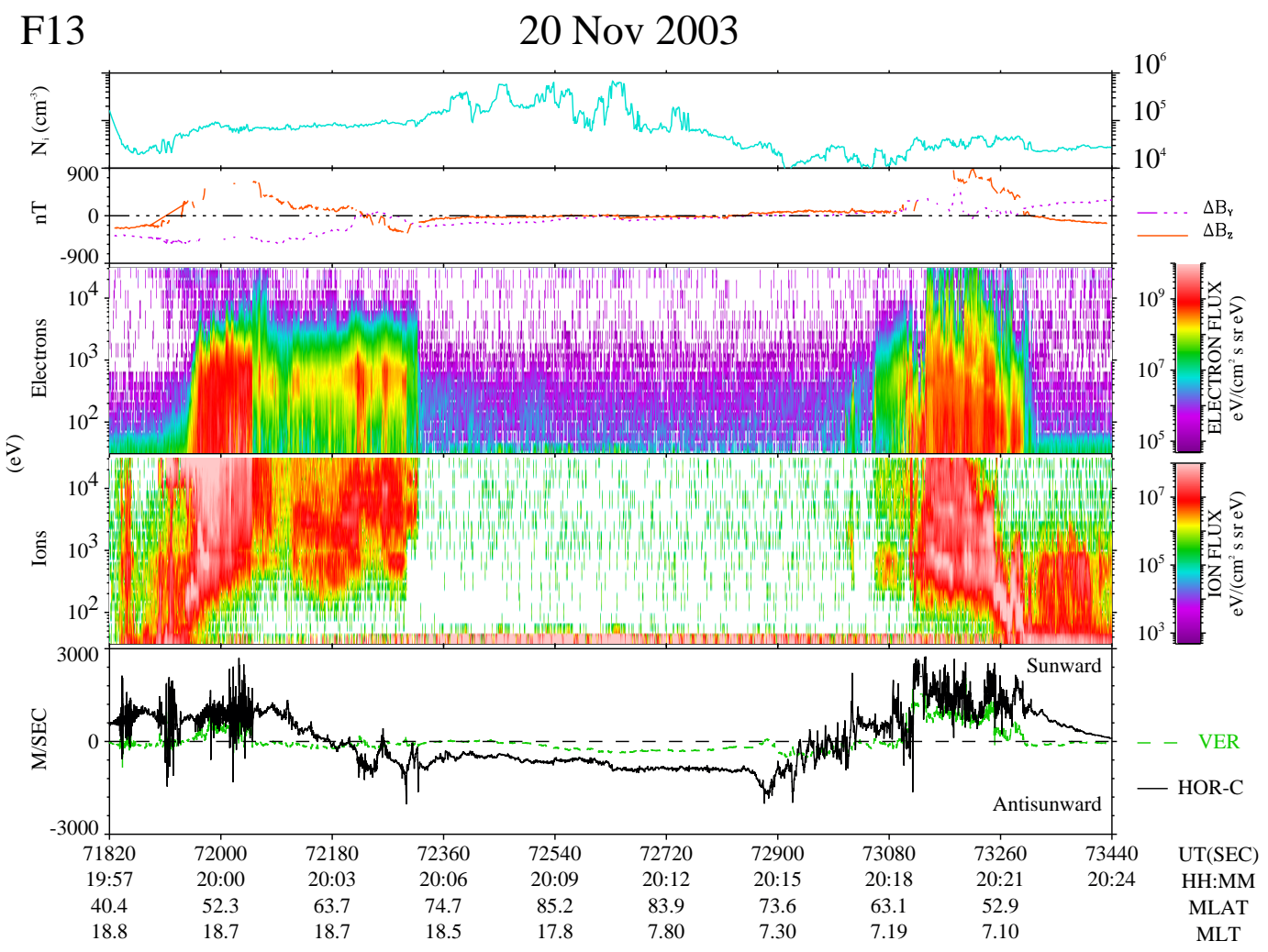

Figure 6. Density, magnetic field, electron and ion fluxes, and drift velocities measured by DMSP-F13 satellite on 20 November 2003 . Note the density enhancements observed within the polar cap after 20:06 UT.

analysis of two consecutive images. We compare our results with the magnitude and direction of the velocities provided by the SuperDARN potential patterns. By using images separated only by $2 \mathrm{~min}$, we avoid drastic changes in the airglow view of polar cap patches that may be occurring due to largescale instability processes, or variations in the altitude of the F region.

Earlier estimations by Fukui et al. (1994) of the patch drift velocities using $630.0 \mathrm{~nm}$ images indicated very good agreement between the patch velocities and the plasma drifts measured by a digisonde. They derived the patch drift velocities by tracking the location of the patch center of gravity. Their analysis applied to 43 patches concluded that the patch velocity did not deviate from the antisunward direction more that $150 \mathrm{~m} \mathrm{~s}^{-1}$. More recently, an automated estimation of the patch drift velocity conducted by Hosokawa et al. (2006) reproduced the close control of the IMF $B_{z}$ component on the magnitude of the patch motion, and the $B_{y}$ dependence on the direction of the patch drift. The analysis of Hosokawa et al. $(2006,2009)$ consisted of a 2-D cross-correlation algorithm employing grids of $80 \times 80$ pixels to estimate the speed and direction of motion of the polar cap patches.

f7

Our 2-D cross-correlation algorithm uses the image intensities of an area equal to $32 \times 32$ pixels (see Fig. 2 ) and cor- relates these values with the intensities of an identical region in the image gathered 2 min earlier. The full cross-correlation function is obtained by sliding the grid of one image in $x$ and $y$ with respect to the other. The patch velocity is directly proportional to the displacement that has the largest crosscorrelation factor. We selected a grid size smaller than the typical patch extension to allow for multiple drift vector estimations within a single patch. The main requirement of this method is that the spatial gradients and the boundaries of the polar cap patches remain coherent between consecutive images. We have restricted the patch drift calculations for areas above $30^{\circ}$ elevation. We have also considered a reliable estimation of the patch drift velocity only when the correlation factor is above 0.95 . Figure 7 shows the $630.0 \mathrm{~nm}$ image (black and gray contours) and the patch drifts (red vectors) corresponding to 20:37:03 UT displayed in a geographic (left panel) and corrected geomagnetic (CG) coordinate system (right panel). The left panel shows the patch velocity vectors directed eastward that become nearly antisunward in a CG coordinate system. The average magnitude of the vector amplitudes is $\sim 630 \mathrm{~m} \mathrm{~s}^{-1}$ (statistical uncertainty $= \pm 94 \mathrm{~m} \mathrm{~s}^{-1}$ ). The right panel also includes the SuperDARN potential pattern (black and gray contours) corresponding to 20:30 UT and for latitudes poleward of $80^{\circ}$. It is worth mentioning that, during the period analyzed here (20:00-24:00 UT) of 


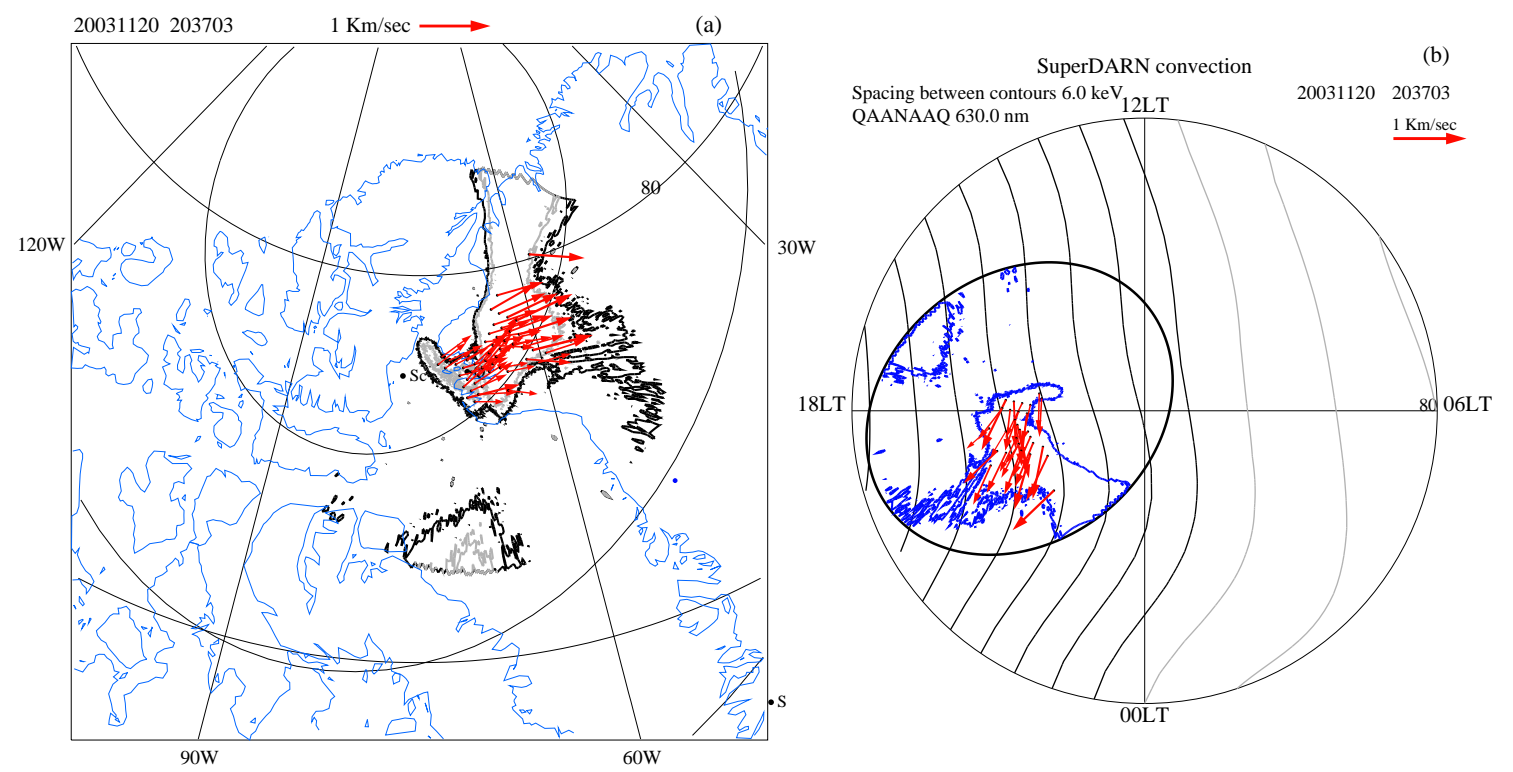

Figure 7. Airglow images (black and gray in left panel, and blue in the right panel) and vectors of the patch drift velocities (in red) plotted in a geographic frame (left panel) and CG polar plot (right panel). The oval shaped lines of (a) indicate the locations of CG latitudes equal to 86 and $82^{\circ}$, respectively. Notice the SuperDARN convection pattern corresponding to 2030 UT is also included in (b). Vectors were obtained by using a 2-D cross-correlation analysis that includes images for 20:35 and 20:37 UT.

the super-storm of 20 November 2003, plasma structuring within the polar cap was abundant, making it possible for the SuperDARN radars to have numerous measurements of LOS velocity, especially on the dusk side of the polar cap. Close comparison between the patch vectors and the SuperDARN flows (not displayed) indicates an average difference of $87 \mathrm{~m} \mathrm{~s}^{-1}$ for the magnitude of the velocities and a $30^{\circ}$ average angle difference.

Figure 8 shows the patch outlines, the SuperDARN convection contours, and the patch vectors for four selected images obtained a few minutes after the image of Fig. 7. These panels show that the patch velocities are mainly antisunward, containing average amplitudes and uncertainties equal to $560 \pm 74,600 \pm 87,730 \pm 129$, and $460 \pm 70 \mathrm{~m} \mathrm{~s}^{-1}$. The sudden decrease in the magnitude of the patch vector in the last panel is followed by smaller SuperDARN velocities and consequently an increase in the separation of the potential contours. Reasonably good agreement between the vector directions and the SuperDARN contours is seen as the differences are comparable to the patch drift velocity uncertainties.

\section{A trajectory analysis technique}

Trajectory analysis is a numerical technique that consists of transporting, backward or forward in time, the ground location of quasi-vertical field lines based on the best estimate of the ionospheric $\boldsymbol{E} \times \boldsymbol{B}$ velocity field (Crowley et al., 2000). A trajectory analysis technique, based on maps of ionospheric convection obtained from the assimilative map- ping of ionospheric electrodynamics (AMIE) technique, was used by Bust and Crowley (2007) to indicate that some of the patches detected by the EISCAT Svalbard radar on 12 December 2001 were part of the TOI. We have used a trajectory analysis algorithm to step backward in time the outline locations of several patches observed between 20:41 and 21:29 UT. Our analysis includes time steps equal to $30 \mathrm{~s}$ as well as velocities determined by the SuperDARN convection patterns with a $10 \mathrm{~min}$ cadence time. The time step was short enough to assure reliable backward tracing along equipotential contours. The patch boundaries were defined by using the locations of the contours corresponding to $80 \mathrm{R}$ airglow enhancements (green traces of Fig. 3). One of the goals of the trajectory analysis technique was to inspect the characteristics of the velocities and the nature of the coherent echoes recorded by the Kapuskasing radar at the time and location when the back-traced locations were near the dayside throat region.

Figure 9 shows the results of a trajectory analysis in which the images of 20:41:03 (red), 21:01:03 (blue), and 21:29:03 UT (green) are used to define the patch boundaries. The upper (lower) panels of Fig. 9 show the back-traced location of the patches at two instances separated by $10 \mathrm{~min}$ displayed in a CG (geographic) coordinate system. The "red" and "blue" patches delineate regions where the number density is higher than the background polar cap density. The shape of these two patches suggests that they have been part of a much larger entity that was probably "broken up" by a formation mechanism. The location of the patches in the convection pattern of Fig. 9 suggests that they originated 

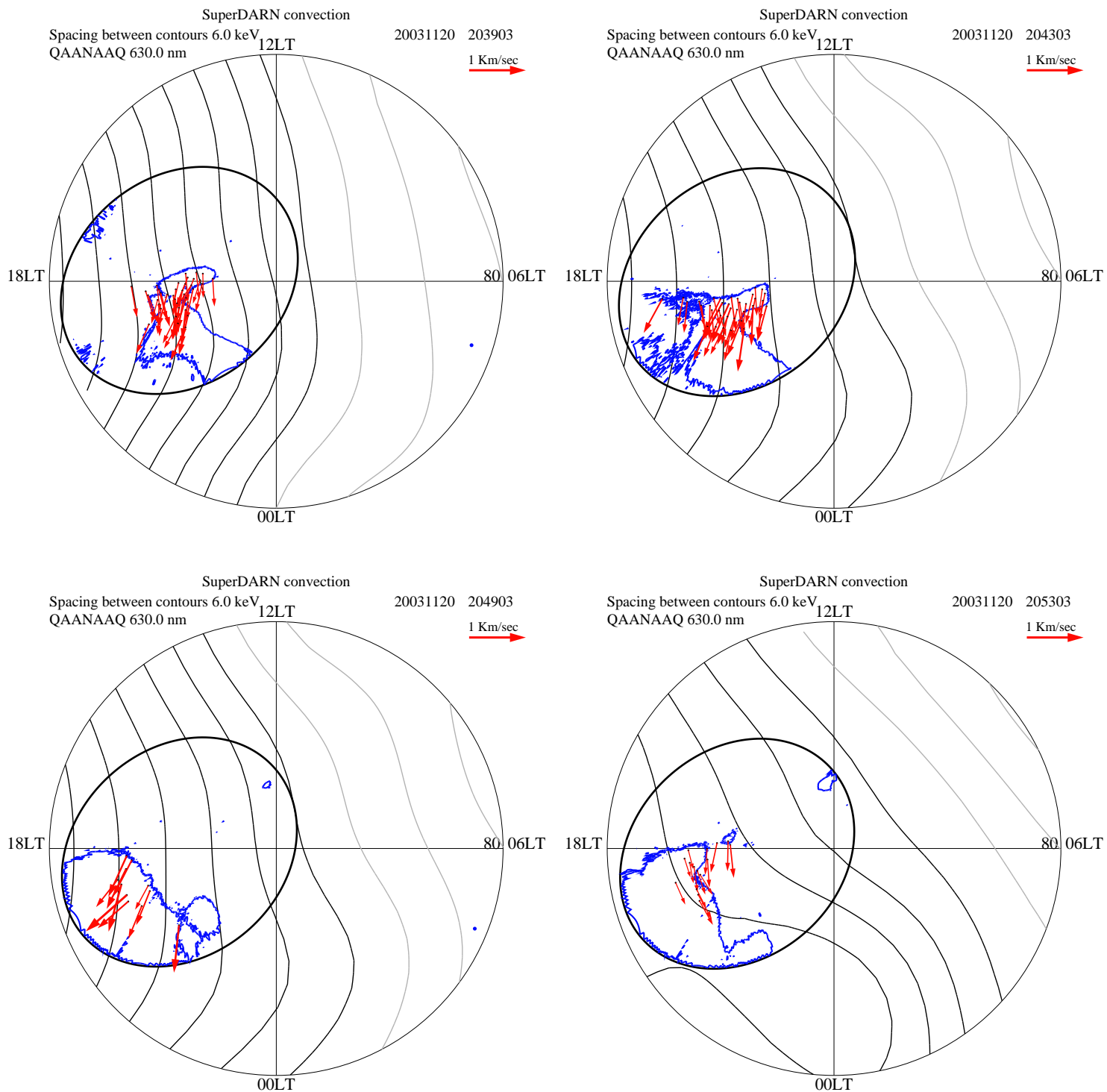

Figure 8. Series of polar cap patches (blue contour) and the patch drift velocity (red vectors) presented in a polar display of CG latitude versus CG local time coordinates. The format of each panel is similar to Fig. $7 \mathrm{~b}$.

from the high-latitude afternoon sector and were transiting the throat region (above Hudson Bay, Canada) between 19:41 and 19:51 UT.

Figure 10 shows the LOS velocity measured by the Kapuskasing radar for the periods of 19:40-19:41:32 and 19:42-19:43:32 UT on 20 November 2003. Both panels indicate the presence of velocities directed poleward (antisunward) at all locations over Hudson Bay (yellow traces). The important feature of these two plots is the small region of enhanced velocities $\left(1.7 \mathrm{~km} \mathrm{~s}^{-1}\right.$, green pixels) seen near the center of the radar scan. The left panel shows the enhanced velocity to be below $70^{\circ}$, and to be in close proximity with the location of the gap that is observed between the red and blue patches in the lower panels of Fig. 9. The panel that starts at 19:42 UT in Fig. 10 (right side) displays a much longer and slightly wider channel that almost coincides geographically with the gap region between the red and blue patches. The east side of the plasma enhancement (green pixels) shows a sharp gradient, suggesting a certain degree of confinement. We also inspected the velocities from the adjacent panels to conclude that the $1.7 \mathrm{~km} \mathrm{~s}^{-1}$ velocities were restricted to three consecutive scans $(\sim 6 \mathrm{~min})$. They decayed before 19:46 UT. Figures 9 and 10 suggest an association between the existence of a region of large plasma velocities and the region of low densities within the patches. Rodger et al. (1994) and Valladares et al. (1994) provide evidence of channels of large flows, or plasma jets, splitting the TOI and forming smaller discrete entities. The peak magnitude of the enhanced plasma velocity is smaller than the value reported by Valladares et al. (1994); however, a localized region con- 

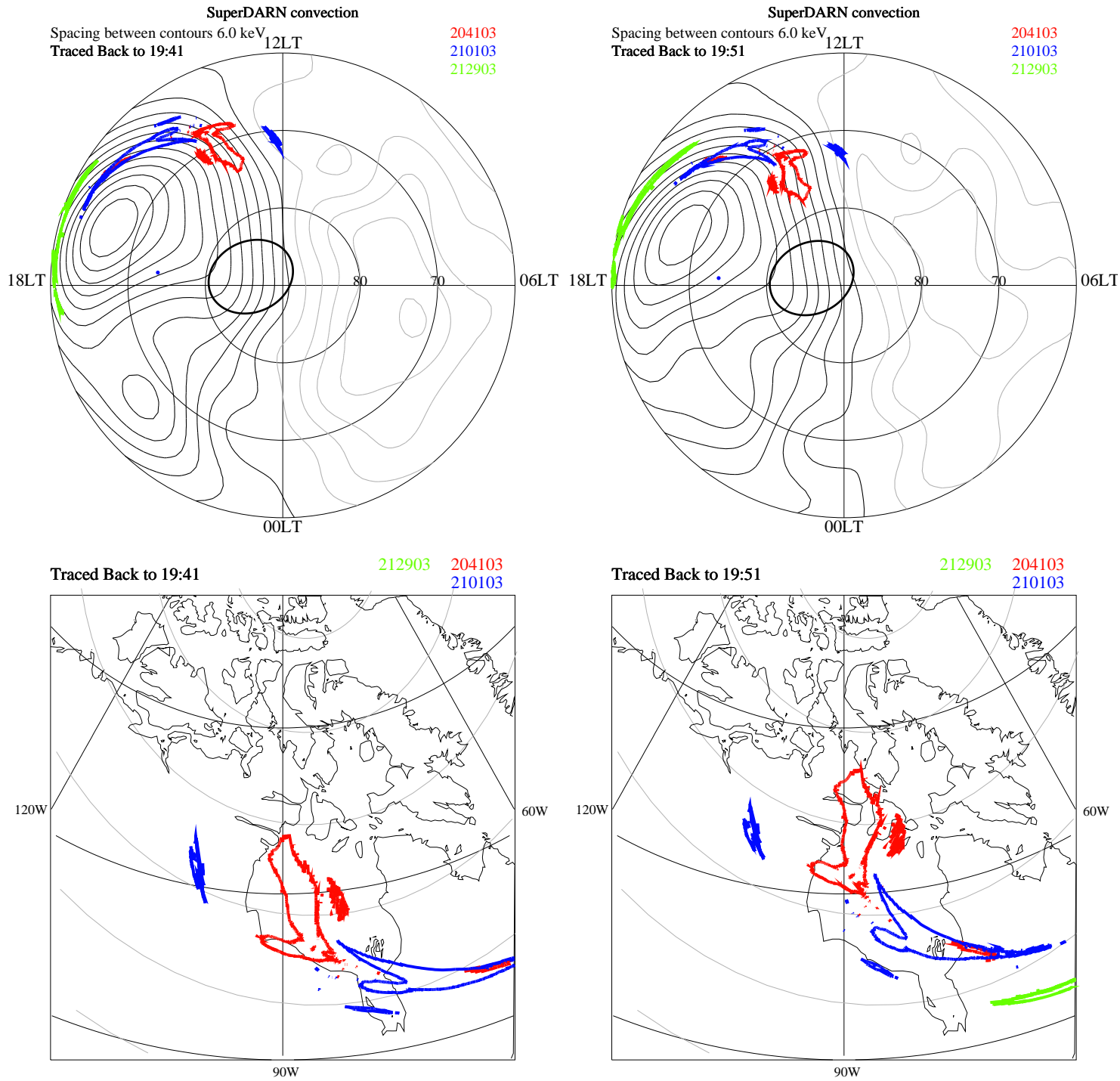

Figure 9. Trajectory analysis of the patches observed at Qaanaaq on 20 November 2003 at 20:41 (red), 21:01 (blue), and 21:29 UT (green). The images were traced backward in time to 19:41 and 19:51 UT. The top panels show the patches in a CG system. The lower panels show the same information in geographic coordinates. The gray lines in the lower panels indicate constant magnetic latitudes between 85 and $70^{\circ}$.

taining plasma drifts of $1.7 \mathrm{~km} \mathrm{~s}^{-1}$, or a set of twin vortices with a central region of $1.7 \mathrm{~km} \mathrm{~s}^{-1}$ velocities, should be able to produce large Joule heating, increase the recombination coefficient, and form regions of reduced densities.

\section{Modeling}

We have used the Global Theoretical Ionospheric Model (GTIM) of the high-latitude ionosphere to investigate the possibility whether a small downward vertical wind associated with a large-scale propagating gravity wave is able to increase the amount of $630.0 \mathrm{~nm}$ airglow emissions. GTIM is based on the numerical code initially developed by Anderson $(1971,1973)$ for the low-latitude ionosphere, but has been extensively modified to correctly simulate the effect on the TOI density produced by a variable polar cap size (Anderson et al., 1988), to reproduce highly structured densities as observed at Sondrestrom, Greenland (Decker et al., 1994), to define the role of large plasma jets and traveling vortices on patch formation (Valladares et al., 1996), and to model boundary blobs (Anderson et al., 1996). The high-latitude GTIM is a 1-D ionospheric model that calculates the ion density by numerically solving the time-dependent $\mathrm{O}^{+}$continuity equation along a flux tube. However, the model can attain a three-dimensionality by repeating the calculations along several flux tubes. GTIM includes the effect of ionization by solar EUV radiation and electron precipitation, loss through charge exchange with $\mathrm{N}_{2}$ and $\mathrm{O}_{2}$, transport by diffu- 


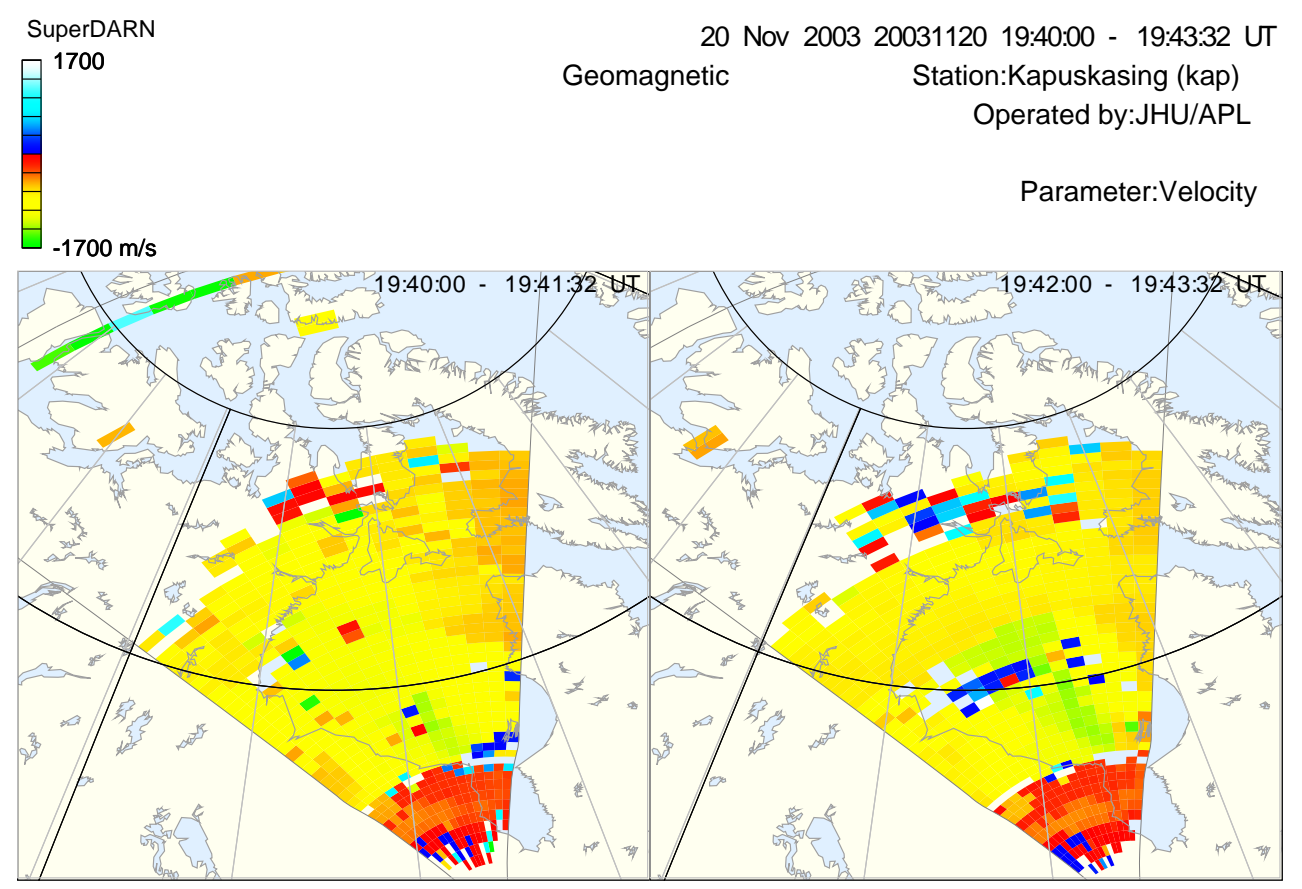

Figure 10. Distance-time plots of Doppler velocity (defined positive toward the radar) observed by the Kapuskasing radar. Note the channel of large negative values $\left(\sim 1500 \mathrm{~m} \mathrm{~s}^{-1}\right)$ seen in the panel of 19:42-19:43:32 UT

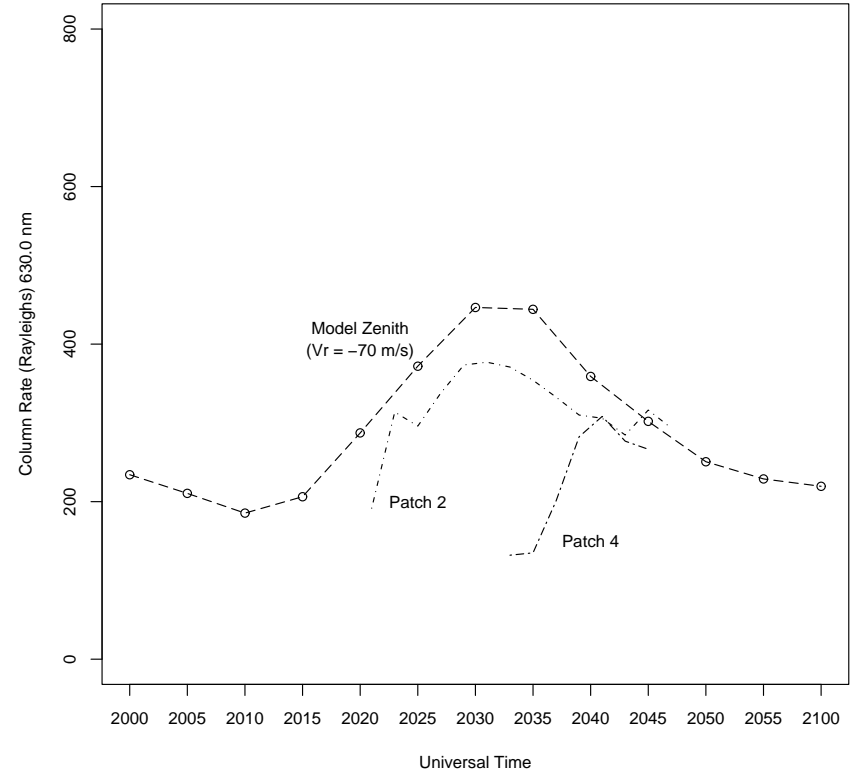

Figure 11. Model column emission rates of atomic oxygen arising from radiative recombination (dashed line and open circles), and $630.0 \mathrm{~nm}$ airglow emissions corresponding to patches 2 and 4 plotted using dot-dash lines.

sion, neutral winds, and $\boldsymbol{E} \times \boldsymbol{B}$ convection drifts. The MSIS and Hedin's wind models supply neutral densities and winds, respectively, and an option to specify a value for the vertical wind was added to see its effect on density profiles. We

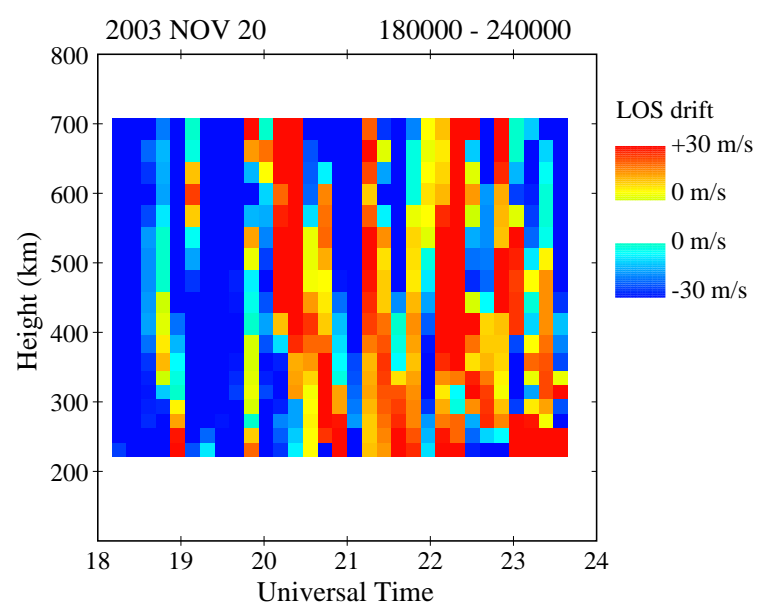

Figure 12. Line-of-sight (LOS) velocities measured by the Sondrestrom radar on 20 November 2003, when the antenna was pointing in the direction parallel to the local magnetic field.

also modified GTIM by including a parameterized model of soft electron precipitation, a calculation of the $\boldsymbol{E} \times \boldsymbol{B}$ plasma drift based upon the SuperDARN convection patterns, and a first-order approximation of the $\mathrm{NO}^{+}$density based on chemical equilibrium.

During the 1990s the Dynamics Explorer 2 satellite discovered the existence of vertical velocity perturbations within the polar cap of the order of $100 \mathrm{~m} \mathrm{~s}^{-1}$ containing horizontal wavelengths along the satellite path of $\sim 500 \mathrm{~km}$ 
that occur in association with the transit of large-scale gravity waves during magnetically active periods (Johnson et al., 1995). Based on these observations, we decided to investigate, numerically, the effect that a vertical wind could have on the airglow emissions associated with the polar cap patches that were circulating during the super-storm of November 2003.

We have modeled the ionospheric density along flux tubes that transited over Qaanaaq between 20:00 and 21:00 UT on 20 November 2003. The simulation was initiated by tracing these flux tubes backward in time until they were passing over the dayside throat region. At these locations, densities along the flux tubes were made equal to the density profile measured by the Millstone Hill (53 ${ }^{\circ}$ CGLAT) radar (Foster et al., 2005). The model proceeds by conducting a full solution of GTIM along a forward tracing of the convection path. The initial density profile was measured near the cusp region at 17:30 UT (their Fig. 8) and characterized the SED/TOI plasma containing densities above $10^{6} \mathrm{~cm}^{-3}$ near $500 \mathrm{~km}$ altitude. Although the path calculation is restricted to the limits of the SuperDARN data $\left(60-90^{\circ}\right.$ CGLAT), this initial profile is probably a reasonable one given the overall magnetic storm condition and the fact that we are not trying to closely reproduce the densities observed at Qaanaaq but rather to study the effect that a vertical wind has on the emission rates associated with polar cap patch densities. However, we noticed that doubling the amount of atomic oxygen provided by the MSIS model increased the F-region peak altitude to values closer to the values measured by the Qaanaaq digisonde. To assess the effect of a burst of vertical wind, we introduced a nominal $70 \mathrm{~m} \mathrm{~s}^{-1}$ downward vertical wind that lasts from 20:10 to 20:30 UT. This wind produces a downward component parallel to the nearly vertical magnetic field lines and causes the peak altitude to descend few tens of kilometers. We also noticed that the number density at $300 \mathrm{~km}$ altitude increased from $2 \times 10^{4}$ to $2 \times 10^{5} \mathrm{~cm}^{-3}$ and the shape of the F-region bottomside varied when the vertical wind was applied. The new density profiles over Qaanaaq were used to estimate the $630.0 \mathrm{~nm}$ column emission rate, $J_{6300}$, in rayleighs due to dissociative recombination using Eq. (1) derived by Tinsley and Bittencourt (1975).

$J_{6300}=\int \frac{A_{6300 \gamma_{1} n}\left(\mathrm{O}_{2}\right) n\left(\mathrm{O}^{+}\right) \mathrm{d} z}{A(1+\mathrm{d}(z) / A)}$,

where $\gamma_{1}$ is the $\mathrm{O}^{+}$and $\mathrm{O}_{2}$ rate coefficient, $A$ is the radiative transition coefficient for the ${ }^{1} \mathrm{D}$ term, and $\mathrm{d}(z)$ is the quenching frequency given by

$\mathrm{d}(z)=S_{\mathrm{N}_{2}} n\left(\mathrm{~N}_{2}\right)+S_{\mathrm{e}} n(e)$,

where $S_{\mathrm{N}_{2}}$ and $S_{\mathrm{e}}$ are the quenching coefficients for quenching on $\mathrm{N}_{2}$ and electrons, respectively.

The dashed line of Fig. 11 shows the column rate as a function of time calculated using Eqs. (1) and (2). A maximum increase equal to $260 \mathrm{R}$ was obtained during the simulations.
Figure 11 also shows the relative brightness of patches 2 and 4 (see Fig. 3) as they transited across the imager field of view. It is observed that patch 2 brightened by $\sim 200 \mathrm{R}$ and that patch 4 , located further sunward (westward in geographic coordinates), increased by $170 \mathrm{R}$.

To strengthen our claim on the presence of a downward motion of the ionosphere, we present Fig. 12, which shows the LOS velocities measured by the Sondrestrom ISR on 20 November 2003, when the radar was pointing along the magnetic field (upward $\boldsymbol{B}$ ). This figure displays alternating bands of upward (red) and downward drift velocities (blue) with a 40-60 min periodicity. Plasma drifts reaching values up to $\pm 50 \mathrm{~m} \mathrm{~s}^{-1}$ were observed between 19:50 and 23:00 UT. It is well known that, when the ISR antenna is pointed parallel to $\boldsymbol{B}$, the radar is able to measure the magnitude of the component of the neutral winds along the magnetic field. As the ionosphere plasma drifts in the $\boldsymbol{E} \times \boldsymbol{B}$ direction, any plasma motion along $\boldsymbol{B}$ is closely related to the neutral wind component in the upward $\boldsymbol{B}$ direction. We suggest that the upward, and then downward, neutral wind motions are due to the passage of a train of large-scale gravity waves. During the major magnetic storm of 20 November 2003, the Sondrestrom radar made observations along the $\boldsymbol{B}$ field that were interleaved with the composite scans (Fig. 4) with a repetition period of $\sim 10.5 \mathrm{~min}$. We also indicate that the Sondrestrom ISR is located about $1300 \mathrm{~km}$ south of the Qaanaaq imager. The Sondrestrom radar measured a downward velocity in the bottomside F region between 19:50 and 20:20 UT. As large-scale TIDs (traveling iosnosphere disturbances) propagate with an average velocity of $850 \mathrm{~m} \mathrm{~s}^{-1}$, it is concluded that the TID will reach Qaanaaq 25 min later (20:15 UT). This calculation explains the fact that the velocities at Sondrestrom were upward between 20:10 and 20:40 UT, when the patches observed at Qaanaaq were moving downward.

\section{Discussion}

We have presented multi-instrument measurements of polar cap patches that developed during the recovery phase of the 20 November 2003 magnetic storm. Various instruments provided redundant observations of the patch dynamics and structuring (imager, scintillation receiver and the digisonde at QaanaaQ, Sondrestrom ISR, SuperDARN radars, and the DMSP F13 satellite). We have also applied a trajectory analysis technique and a 2-D cross-correlation algorithm and modified the GTIM of the high-latitude ionosphere in order to trace patch locations backward to times when they are crossing the dayside throat region and to investigate the possible effect that a vertical neutral wind has on airglow intensity.

During major magnetic storms, the TOI becomes a dense stream of cold plasma that has a source in the SED density that is transported from much lower latitudes by the SAPS electric field (Foster et al., 2005), there exist severe disruptions of the thermosphere composition as regions of de- 
pleted $\mathrm{O} / \mathrm{N}_{2}$ ratios extend from high latitudes to the Equator (Meier et al., 2005; Crowley et al., 2006), and there is a penetration of the interplanetary electric field (Huang et al., 2006) that reaches the equatorial ionosphere and generates a much larger fountain effect that is able to transport the anomaly crests to $20^{\circ}$ or more away from the magnetic equator. These mechanisms provide a polar cap ionosphere rich in unusually high plasma density and gradients.

Weber et al. (1986), and Basu et al. (1988) pointed out that the gradient drift instability (GDI) was responsible for the onset of mesoscale $(10 \mathrm{~km}$ to $100 \mathrm{~m})$ irregularities within the polar cap patches. While the linear GDI is only unstable on the trailing edge of the patch, in the nonlinear regimen GDI predicts the development of mesoscale structures that propagate from the unstable edge, through the patch, and reach the stable side (Gondarenko et al., 2003; Gondarenko and Guzdar, 2004). On 20 November 2003, we observed that the density spikes seen at 20:33 and 20:57 UT (Fig. 1c) have corresponding high airglow enhancements and significant levels $(\sim 0.6)$ of UHF scintillations. However, between 19:50 and 20:20 UT, when the number density was only half $\left(10^{6} \mathrm{~cm}^{-3}\right)$ of the density observed at 20:33 UT, the scintillation S4 index was saturated. This nonlinear relationship between number density and the S4 index indicates the importance of making a full estimate of the plasma conditions associated with the patches. It is necessary to measure the plasma drift in the neutral frame of reference, the density gradient, and the temporal evolution of the electric fields, and probably necessary to know the formation mechanism of the polar cap patch. These parameters dictate the level of plasma structuring that develops within a patch. We also note that a small time lag ( $3 \mathrm{~min}$ ) should be considered due to the offset distance of the scintillations sub-ionospheric penetration point and the zenith direction.

To the best of our knowledge, patch brightenings as observed on 20:37 UT have never been documented before. We hypothesized that this aspect of the patch evolution on 20 November 2003 could be attributed to the passage of largescale gravity waves. These waves have been observed inside the polar cap by Johnson et al. (1995) (W. B. Hanson, personal communication, 1993) during magnetically disturbed periods. We do not have simultaneous measurements of the neutral atmosphere conditions during the period under study. However, the Sondrestrom ISR observed oscillatory (e.g., up and down) LOS velocities when the antenna was looking along the local field line. It is also important to indicate that the Qaanaaq digisonde measured a density contour corresponding to $10^{5} \mathrm{~cm}^{-3}$, showing a downward progression starting at 20:10 UT. To compare the model results and the airglow measurements, we quantified the calibrated enhancement of 630.0 airglow emissions associated with patches labeled "2" and "4" (Fig. 3) as they transited across the imager field of view. We measured a rapid increase of 200 and $170 \mathrm{R}$ for patches 2 and 4, respectively. It is important to mention that these measurements were carried out when the patches were located above $25^{\circ}$ elevation. We conducted numerical simulations of the polar ionosphere incorporating a vertical thermospheric wind into the 1-D equations of continuity and momentum. A $70 \mathrm{~m} \mathrm{~s}^{-1}$ downward wind was applied between 20:10 and 20:30 UT to mimic the behavior of the gravity wave passing above the station. A downward vertical wind will bring higher density F-region plasma to lower altitudes, increasing the recombination of F-region plasma. Our results indicated an airglow enhancement equal to $265 \mathrm{R}$, or $25 \%$ higher than the enhancement of patch 2 . A more precise simulation can be conducted if good estimates of the $\mathrm{O} / \mathrm{N}_{2}$ ratio, the initial density at the throat region, and the value of the downward wind are gathered (Barbier et al., 1962; Sojka et al., 1997; Sakai et al., 2014). However, the numerical results of the effects that a small vertical component of the wind can generate on patch airglow emissions are very encouraging. These calculations also support our hypothesis that a train of large-scale gravity waves can be responsible for the variation in airglow emissions.

We have applied a trajectory analysis algorithm to airglow contours of images observed at the Qaanaaq station to investigate the origin and the formation mechanism of polar cap patches. Bust and Crowley (2007) backtracked observations from the EISCAT Svalbard radar to conclude that some of the patch density had originated in the morning side. MacDougall and Jayachandran (2007) also suggested that the origin of the patches observed inside the polar cap could be in the dawn cell. Moen et al. (2007) indicated that the patches could equally exit and then re-enter from the dawn and dusk cells. Our trajectory analysis helps us to conclude that the majority of the patches observed on 20 November 2003 during a major magnetic storm - were originated in the afternoon side, transported into the polar cap by the polar convection, and probably formed (broken up) by processes related to the cusp electrodynamics. Two consecutive scans conducted by the Kapuskasin radar have indicated the existence of a channel containing a flow near $1.7 \mathrm{~km} \mathrm{~s}^{-1}$ that coincides, considering a small offset due to uncertainties of the trajectory analysis, with the region that is in between the patches. We suggest that, at 19:41 UT, plasma originated from the afternoon region was about to enter the polar cap when a narrow channel of $1.7 \mathrm{~km} \mathrm{~s}^{-1}$ velocities, which probably was originated in association with the cusp, increased the Joule heating, the ion temperature, and the $\mathrm{O}^{+}$recombination rate. We also indicate that the large plasma jet of $1.7 \mathrm{~km} \mathrm{~s}^{-1}$ contained shears on both sides of the jet that not only seed other type of instabilities (Carlson, 2012) but also move flux tubes at different locations helping to dissect the otherwise continuous TOI. The temporal and spatial collocation between the large flow and the patch gap suggests a relationship between these two structures and raises the possibility that the patches of 19:41 UT (Fig. 9) were formed by the large plasma jet mechanism. It is also important to mention that Moen et al. (2006) found patches that were segmented equatorward of the cusp/cleft region by downward Birkeland current sheets. 
A similar scenario may have happened here, but we do not have evidence for its occurrence.

We have used $630.0 \mathrm{~nm}$ images of polar cap patches and the principle that polar cap patches drift almost unchanged with the background $\boldsymbol{E} \times \boldsymbol{B}$ convection to derive the magnitude and direction of the underlying convection. We obtained vector velocities which were in good agreement with measured SuperDARN drifts.

\section{Conclusions}

This study has led to the following:

1. The polar cap patches observed during the recovery phase of the large geomagnetic storm of 20 November 2003 showed that their $630.0 \mathrm{~nm}$ airglow intensities can vary as much as $250 \mathrm{R}$ as they transit across the imager field of view. We used GTIM to investigate whether a downward neutral wind associated with a train of largescale gravity waves could be responsible for the variable intensity of the $630.0 \mathrm{~nm}$ airglow emissions.

2. The GTIM code was modified to accept SuperDARNderived polar convection patterns and a variable value of the vertical component of the thermospheric wind. We were able to calculate that a $70 \mathrm{~m} \mathrm{~s}^{-1}$ downward vertical wind acting on the same field line for $20 \mathrm{~min}$ could produce an increase of $250 \mathrm{R}$ in the $630.0 \mathrm{~nm}$ airglow emissions, supporting the role of gravity waves in increasing airglow emissions.

3. The development of a back-tracing trajectory analysis algorithm allowed us to investigate the origin of the polar cap patches. We concluded that, during the interval under study, most of the patches entered the polar cap from the afternoon sector.

4. Continuous measurements conducted by the Kapuskasing SuperDARN radar provided evidence for the presence of enhanced velocities $\left(>1.7 \mathrm{~km} \mathrm{~s}^{-1}\right)$ on 20 November 2003. The use of a tracing algorithm able to step backwards in time permits us to examine the ionospheric condition when the patches were in the dayside region. This algorithm can be applied to other patch events to study the formation mechanism of polar cap patches when the ionosphere is in a non-storm condition.

5. A method to calculate plasma drift velocity that uses a 2-D cross-correlation algorithm has been developed based on the property of the patches to drift with the background polar cap convection. We used the SuperDARN polar convection to validate our drift results.
Acknowledgements. The authors thank Simon Shepherd for taking the time to conduct analysis of the SuperDARN velocities. We also thank Dwight Decker and David Anderson for useful insights into GTIM and for helping us to develop a way to calculate molecular ions and red-line emission intensities. We acknowledge Santimay Basu for providing useful suggestions for improving the paper. We thank Eileen MacKenzie for providing data from the scintillation system at Thule, Greenland. The work at Boston College was partially supported through Air Force Research Laboratory contract FA8718-09-C-0041 and NSF grants ATM-1135675 and ATM1242476. Data collection and analysis at AFRL were supported by the Air Force Office of Scientific Research. The Sondrestrom ISR and the SuperDARN radar program receive support from the US National Science Foundation (NSF) Upper Atmosphere Facilities Program.

The topical editor K. Hosokawa thanks H. Carlson and one anonymous referee for help in evaluating this paper.

\section{References}

Anderson D. N.: Daily variation of the ionospheric F2 equatorial anomaly in the American and Asian sectors, cooperative thesis, Natl. Cent. Atmos. Res., Boulder, Colo., 24 pp., 1971.

Anderson D. N.: A theoretical study of the ionospheric F region equatorial anomaly, I, Theory, Planet. Space Sci., 21, 409-419, 1973.

Anderson, D. N., Buchau, J., and Heelis, R. A.: Origin of density enhancements in the winter polar cap ionosphere, Radio Sci., 23, 513-519, 1988.

Anderson, D., Decker, D., and Valladares, C.: Modeling Boundary Blobs Using Time Varying Convection, Geophys. Res. Lett., 23, 579-582, 1996.

Barbier, D., Roach, F. E., and Steiger, W. R.: The summer intensity variations of [OI] 6300 in the tropics, J. Res. NBS - D. Radio Propagation, 66D, 145-152, 1962.

Basu, S., Basu, S., MacKenzie, E., Fougere, P. F., Coley, W. R., Maynard, N. C., Winningham, J. D., Sugiura, M., Hanson, W. B., and Hoegy, W. R.: Simultaneous Density and Electric Field Fluctuation Spectra Associated with Velocity Shears in the Auroral Oval, J. Geophys. Res., 93, 115-136, 1988.

Basu, S., Weber, E. J., Bullett, T. W., Keskinen, M. J., MacKenzie, E., Doherty, P., Sheehan, R., Kuenzler, H., Ning, P., and Bongiolatti, J.: Characteristics of plasma structuring in the cusp/cleft region at Svalbard, Radio Sci., 33, 1885-1899, 1998.

Basu, S., Basu, S., Rich, F. J., Groves, K. M., MacKenzie, E., Coker, C., Sahai, Y., Fagundes, P. R., and Becker-Guedes, F.: Response of the equatorial ionosphere at dusk to penetration electric fields during intense magnetic storms, J. Geophys. Res., 112, A08308, doi:10.1029/2006JA012192, 2007.

Buchau, J., Reinisch, B. W., Weber, E. J., and Moore, J. G.: Structure and dynamics of the winter polar cap $F$ region, Radio Sci., 18, 995-1010, 1983.

Buchau, J., Weber, E. J., Anderson, D. N., Carlson Jr., H. C., Moore, J. G., Reinisch, B. W., and Livingston, R. C.: Ionospheric structures in the polar cap: Their origin and relation to $250-\mathrm{MHz}$ scintillation, Radio Sci., 20, 325-338, 1985. 
Bust G. S. and Crowley, G.: Tracking of polar cap ionospheric patches using data assimilation, J. Geophys. Res., 112, A05307, doi:10.1029/2005JA011597, 2007.

Carlson, H. C.: Sharpening our thinking about polar cap ionospheric patch morphology, research, and mitigation techniques, Radio Sci., 47, RSOL21, doi:10.1029/2011RS004946, 2012.

Carlson, H. C., Oksavik, K., Moen, J., van Eyken, A. P., and Guio, P.: ESR mapping of polar-cap patches in the dark cusp, Geophys. Res. Lett., 29, 1386, doi:10.1029/2001GL014087, 2002.

Carlson, Jr., H. C., Oksavik, K., Moen, J., and Pedersen, T.: Ionospheric patch formation: Direct measurements of the origin of a polar cap patch, Geophys. Res. Lett., 31, L08806, doi:10.1029/2003GL018166, 2004.

Carlson, H. C., Moen, J., Oksavik, K., Nielsen, C. P., McCrea, I. W., Pedersen, T. R., and Gallop, P.: Direct observations of injection events of subauroral plasma into the polar cap, Geophys. Res. Lett., 33, L05103, doi:10.1029/2005GL025230, 2006.

Carlson, H. C., Pedersen, T., Basu, S., Keskinen, M., and Moen, J.: Case for a new process, not mechanism, for cusp irregularity production , J. Geophys. Res., 112 , A11304, doi:10.1029/2007JA012384, 2007.

Crowley, G.: Critical review of ionospheric patches and blobs, in: The Review of Radio Science, edited by: Moen, J., Egeland, A., Lockwood, M., Oxford Univ. Press, New York, p. 1, 1996.

Crowley, G., Ridley, A. J., Deist, D., Wing, S., Knipp, D. J., Emery, B. A., Foster, J., Heelis, R., Hairston, M., and Reinisch, B. W.: Transformation of high-latitude ionospheric $F$ region patches into blobs during the March 21, 1990, storm, J. Geophys. Res., 105, 5215-5230, 2000.

Crowley, G., Hackert,C. L., Meier, R. R., Strickland, D. J., Paxton, L. J., Pi, X., Mannucci, A., Christensen, A. B., Morrison, D., Bust, G. S., Roble, R. G., Curtis, N., and Wene, G.: Global thermosphere-ionosphere response to onset of 20 November 2003 magnetic storm, J. Geophys. Res., 111, A10S18, doi:10.1029/2005JA011518, 2006.

Decker, D., Valladares, C., Sheehan, R., Basu, S., Anderson, D., and Heelis, R.: Modeling daytime F layer patches over Sondrestrom, Radio Sci., 29, 249-268, 1994.

Foster, J. and Doupnik, J.: Plasma Convection in the Vicinity of the Dayside Cleft, J. Geophys. Res., 89, 9107-9113, 1984.

Foster, J. C. and Burke, W. J.: SAPS: A new categorization for subauroral electric fields, Eos Trans. AGU, 83, 393-394, 2002.

Foster, J. C., Coster, A. J., Erickson, P. J., Holt, J. M., Lind, F. D., Rideout, W., McCready, M., van Eyken, A., Barnes, R. J., Greenwald, R. A., and Rich, F. J.: Multiradar observations of the polar tongue of ionization, J. Geophys. Res., 110, A09S31, doi:10.1029/2004JA010928, 2005.

Fukui, K., Buchau, J., and Valladares, C. E.: Convection of polar cap patches observed at Qaanaaq, Greenland during the winter of 1989-1990, Radio Sci., 29, 231-248, 1994.

Gondarenko, N. A., Guzdar, P. N., Sojka, J. J., and David, M.: Structuring of high latitude plasma patches with variable drive, Geophys. Res. Lett., 30, 1165, doi:10.1029/2002GL016437, 2003.

Gondarenko, N. A. and Guzdar, P. N.: Density and electric field fluctuations associated with the gradient drift instability in the high-latitude ionosphere, Geophys. Res. Lett., 31, L11802, doi:10.1029/2004GL019703, 2004.

Gopalswamy, N., Yashiro, S., Michalek, G., Xie, H., Lepping, R. P., and Howard, R. A.: Solar source of the largest geo- magnetic storm of cycle 23, Geophys. Res. Lett., 32, L12S09, doi:10.1029/2004GL021639, 2005.

Hocke, K. and Schlegel, K.: A review of atmospheric gravity waves and travelling ionospheric disturbances: 1982-1995, Ann. Geophys., 14, 917-940, doi:10.1007/s00585-996-0917-6, 1996.

Hosokawa K., Shiokawa, K., Otsuka, Y., Nakajima, A., Ogawa, T., and Kelly, J. D.: Estimating drift velocity of polar cap patches with all-sky airglow imager at Resolute Bay, Canada, Geophys. Res. Lett., 33, L15111, doi:10.1029/2006GL026916, 2006.

Hosokawa, K., Kashimoto, T., Suzuki, S., Shiokawa, K., Otsuka, Y., and Ogawa, T.: Motion of polar cap patches: A statistical study with all-sky airglow imager at Resolute Bay, Canada, J. Geophys. Res., 114, A04318, doi:10.1029/2008JA014020, 2009.

Huang, C., Sazykin, S., Spiro, R., Goldstein, J., Crowley, G., and Ruohoniemi, J. M.: Storm-Time Penetration Electric Fields and Their Effects, Eos Trans. AGU, 87, p. 131, doi:10.1029/2006EO130005, 2006.

Johnson, F., Hanson, W., Hodges, R., Coley, W., Carignan, G., and Spencer, N.: Gravity Waves Near 300 km Over the Polar Caps, J. Geophys. Res., 100, 23993-24002, 1995.

Kelly, J. and Vickrey, J.: F-Region Ionospheric Structure Associated with Antisunward Flow near the Dayside Polar Cusp, Geophys. Res. Lett., 11, 907-910, 1984.

Lockwood, M. and Carlson Jr., H. C.: Production of polar cap electron density patches by transient magnetopause reconnection, Geophys. Res. Lett., 19, 1731-1734, 1992.

Lorentzen, D. A., Moen, J., Oksavik, K., Sigernes, F., Saito, Y., and Johnsen, M. G.: In situ measurement of a newly created polar cap patch , J. Geophys. Res., 115 , A12323, doi:10.1029/2010JA015710, 2010.

MacDougall J. and Jayachandran, P. T.: Polar patches: Auroral zone precipitation effects, J. Geophys. Res., 112, A05312, doi:10.1029/2006JA011930, 2007.

Meier, R. R., Crowley, G., Strickland, D. J., Christensen, A. B., Paxton, L. J., Morrison, D., and Hackert, C. L.: First look at the 20 November 2003 superstorm with TIMED/GUVI: Comparisons with a thermospheric global circulation model, J. Geophys. Res., 110, A09S41, doi:10.1029/2004JA010990, 2005.

Moen, J., Carlson, H. C., Oksavik, K., Nielsen, C. P., Pryse, S. E., Middleton, H. R., McCrea, I. W., and Gallop, P.: EISCAT observations of plasma patches at sub-auroral cusp latitudes, Ann. Geophys., 24, 2363-2374, doi:10.5194/angeo-242363-2006, 2006.

Moen, J., Gulbrandsen, N., Lorentzen, D. A., and Carlson, H. C.: On the MLT distribution of $F$ region polar cap patches at night, Geophys. Res. Lett., 34, L14113, doi:10.1029/2007GL029632, 2007.

Oksavik, K., Ruohoniemi, J. M., Greenwald, R. A., Baker, J. B. H., Moen, J., Carlson, H. C., Yeoman, T. K., and Lester, M.: Observations of isolated polar cap patches by the European Incoherent Scatter (EISCAT) Svalbard and Super Dual Auroral Radar Network (SuperDARN) Finland radars, J. Geophys. Res., 111, A05310, doi:10.1029/2005JA011400, 2006.

Oksavik, K., Barth, V. L., Moen, J., and Lester, M.: On the entry and transit of high-density plasma across the polar cap, J. Geophys. Res., 115, A12308, doi:10.1029/2010JA015817, 2010.

Rodger, A. S., Pinnock, M., Dudeney, J. R., Baker, K. B., and Greenwald, R. A.: A New Mechanism for Polar Patch Formation, J. Geophys. Res., 99, 6425-6436, 1994. 
Sakai, J., Hosokawa, K., Taguchi, S., and Ogawa, Y.: Storm time enhancements of $630.0 \mathrm{~nm}$ airglow associated with polar cap patches, J. Geophys. Res., 119, 2214-2228, doi:10.1002/2013JA019197, 2014.

Sojka, J. J., Bowline, M. D., Schunk, R. W., Decker, D. T., Valladares, C. E., Sheehan, R., Anderson, D. N., and Heelis, R. A.: Modeling polar cap $F$-region patches using time varying convection, Geophys. Res. Lett., 20, 1783-1786, 1993.

Sojka, J. J., Schunk, R. W., Bowline, M. D., and Crain, D. J.: Ambiguity in identification of polar cap F-region patches: contrasting radio and optical observation techniques, J. Atmos. Sol. Terr. Phys., 59, 249-258, 1997.

Tinsley, B. A. and Bittencourt, J. A.: Determination of $F$ Region Height and Peak Electron Density at Night Using Airglow Emissions from Atomic Oxygen, J. Geophys. Res., 80, 2333-2337, 1975.

Tsunoda, R.: High-Latitude F Region Irregularities: A Review and Synthesis, Rev. Geophys., 26, 719-760, 1988.

Valladares, C. E., Basu, S., Buchau, J., and Friis-Christensen, E.: Experimental evidence for the formation and entry of patches into the polar cap, Radio Sci., 29, 167-194, 1994.
Valladares, C. E., Decker, D. T., Sheehan, R., and Anderson, D. N.: Modeling the formation of polar cap patches using large plasma flows, Radio Sci., 31, 573-593, 1996.

Valladares, C. E., Fukui, K., Sheehan, R., Carlson Jr., H. C., and Bullett, T.: Simultaneous observations of polar cap patches and Sun-aligned arcs during transitions of the IMF, Radio Sci., 33, 1829-1845, 1998.

Walker, I. K., Moen, J., Kersley, L., and Lorentzen, D. A.: On the possible role of cusp/cleft precipitation in the formation of polar-cap patches, Ann. Geophys., 17, 1298-1305, doi:10.1007/s00585-999-1298-4, 1999.

Weber, E. J., Buchau, J., Moore, J. G., Sharber, J. R., Livingston, R. C., Winningham, J. D., and Reinisch, B. W.: $F$ Layer Ionization Patches in the Polar Cap, J. Geophys. Res., 89, 1683-1694, 1984.

Weber, E. J., Klobuchar, J. A., Buchau, J., Carlson Jr., H. C., Livingston, R. C., de la Beaujardiere, O., McCready, M., Moore, J. G., and Bishop, G. J.: Polar Cap $F$ Layer Patches: Structure and Dynamics, J. Geophys. Res., 91, 12121-12129, 1986. 